\title{
Lithium reduced aggression and was safe in aggressive children and adolescents with conduct disorder admitted to hospital
}

Malone RP, Delaney MA, Luebbert JF, et al. A double-blind placebo-controlled study of lithium in hospitalized aggressive children and adolescents with conduct disorder. Arch Gen Psychiatry 2000 Jul;57:649-54.

QUESTION: In children and adolescents in hospital with conduct disorder and frequent aggression, how effective and safe is lithium in reducing aggression?

\section{Design}

Randomised (unclear allocation concealment*), blinded (patients and outcome assessors)*, placebo controlled trial with 4 weeks of treatment.

\section{Setting}

Acute care child and adolescent psychiatric inpatient service in a teaching hospital in the US.

\section{Patients}

40 inpatients (mean age $13 \mathrm{y}, 83 \%$ boys) with a DSM-III-R diagnosis of conduct disorder. All patients were admitted to hospital with histories of severe aggression and met the aggression criterion during a 2 week placebo baseline period. Exclusion criteria were diagnosis of mental retardation, pervasive developmental disorder, major depressive disorder or dysthymic disorder, bipolar disorder, or psychotic disorder; substance dependence in the previous month; pregnancy; received psychoactive medication within the past 2 weeks; had a previous lithium trial; or had a major medical problem. All patients completed the treatment phase.

\section{Intervention}

20 patients were allocated to lithium, initial dose was 600 $\mathrm{mg}$ /day and was increased by $300 \mathrm{mg}$ /day to a target dose (titrated between 300 and $2100 \mathrm{mg} / \mathrm{d}$ ) with the aim of obtaining a steady state therapeutic concentration of 0.8 to $1.2 \mathrm{mmol} / \mathrm{l}$ and no or minimal side effects. 20 patients were allocated to placebo.

\section{Main outcome measures}

The primary outcome measures were the Global Clinical Judgments (Consensus) Scale (GCJCS), the Clinical Global Impressions (CGI), and the Overt Aggression Scale (OAS).

\section{Main results}

More patients in the lithium group were classified as responders on the GCJCS and CGI (showed moderate or marked improvement) than those in the placebo group ( $p=0.004$ for both scales) (table). Ratings on the OAS decreased more for those in the lithium group than for those in the placebo group (mean decrease at 4 weeks $2.4 v 1.2, \mathrm{p}=0.04$ ). No patients dropped out of the study because of lithium associated side effects even though more patients in the lithium group had nausea, vomiting, and urinary frequency than those in the placebo group $(\mathrm{p}=0.05)$.

\section{Conclusion}

In children and adolescents in hospital with severe aggression and conduct disorder, lithium reduced the frequency and severity of aggression and was well tolerated.

*See glossary. hospitalt

\section{COMMENTARY} mal bipolar disorder, or post-traumatic stress disorder. The only side effect was weight gain. between lithium and divalproex. chiatry 2000;157:818-20.
Source of funding: US Public Health Service.

For correspondence: Dr R P Malone, Department of Psychiatry, MCP Hahnemann

University, Eastern Pennsyluania Psychiatric Institute, 3200 Henry Avenue, Philadelphia, $P A$ 19129, USA. Fax +1 2158496673.

Lithium v placebo at 4 weeks in aggressive children and adolescents with conduct disorder in

\begin{tabular}{|c|c|c|c|c|}
\hline Outcomes & Lithium & Placebo & $\mathrm{RBI}(95 \% \mathrm{CI})$ & NNT (CI) \\
\hline Responder on the GCJCS & $80 \%$ & $30 \%$ & $167 \%(43$ to 464$)$ & 2 (2 to 6$)$ \\
\hline Responder on the CGI & $70 \%$ & $20 \%$ & $250 \%$ (54 to 798$)$ & $2(2$ to 6$)$ \\
\hline
\end{tabular}

This study by Malone et al may be helpful to child psychiatrists working in inpatient or residential care facilities and caring for conduct disordered youth with severe aggressive outbursts, especially those African-American or Hispanic youth from low income backgrounds with conduct disorder who are physically aggressive at least twice weekly. The low number needed to treat shows the efficacy of lithium in reducing aggression in this population. This clear result, however, is tempered by design issues and clinically significant side effects. The treatment staff or research team completed the instruments used to measure treatment response. Side effects like frequent urination and vomiting were noted in the lithium group, leaving the blinding of the staff open to question. Also, the time period was too brief for patients to develop acne from lithium, and no data are offered about the prevalence of important comorbidities like substance use, subsyndro-

For many child psychiatrists the psychopharmacological choices in working with children with conduct disorder and severe aggression might also include divalproex. A comparable study (double blind, crossover) showed clear efficacy for divalproex over placebo in 20 outpatient children and adolescents ( $80 \%$ boys) with a disruptive behaviour disorder (oppositional defiant disorder or conduct disorder), an explosive temper ( $\geqslant 4$ outbursts or fights per month on minimal provocation), and mood lability (multiple daily distinct shifts). ${ }^{1}$ This study population was also composed mainly of minorities $(60 \%$ Hispanic, $25 \%$ African-American) and 6 out of 20 abused marijuana. The number needed to treat to reach improvement defined as a $\geqslant 70 \%$ reduction on a scale of overt aggression was 2 .

Child psychiatrists may wish to compare results from these studies in choosing

John D Hamilton, MD University of California, Davis, School of Medicine, Sacramento, California, USA

1 Donovan SJ, Stewart JW, Nunes EV, et al. Divalproex treatment for youth with explosive temper and mood lability: a double-blind, placebo-controlled crossover design. Am J Psy- 